\title{
Practical Battery Discharge Regulator with Weinberg Topology
}

\author{
Anand E P, Priya G Das
}

\begin{abstract}
A BDR (battery discharge regulator) required to keep battery voltage within acceptable limits and improve life of the battery. A converters with greater reliability, high power density, tolerance to any fault, are needed for BDR in space craft power supply. Weinberg converter topology is suitable meet this specification. This topology can be treated as a modified push-pull converter topology with coupled inductor. Use of coupled inductor makes output current of converter is continuous, which reduces the output filter capacitors requirement. In this, working of converter and its main features are explained and also practically implemented the converter and its results are analyzed.
\end{abstract}

Keywords: Weinberg converter, fault tolerance, battery discharge regulator, coupled inductor

\section{INTRODUCTION}

Power supplies are continually developing to long life, wide range of input voltage, higher power density in recent years. Nowadays, due to the larger energy and power density Lithium based batteries are desired to feed energy for lot of application [1].Lithium based batteries have advantages such as high efficiency, lightweight and compact which not only increase the charging efficiency but also saves power loss by reducing the heat generation on the charging process. Due to the variable battery voltage, power converter always need to demand a solid output voltage under tolerating change at the input voltage. Dc converter need to make the output voltage stable even tolerating the wide range of input voltage [1].Depth of discharge (DoD) of battery need to be consider in order to extend the life time of batteries. Battery lifetime can be lengthened by regulating the DoD at most 50\% [2]. For maintain constant bus voltage in all conditions, battery need to connect to power bus through a DC-DC power converter, also known as BDR [5]. Converter used in BDR should be a buck type converter because voltage of the battery is normally kept above the DC bus voltage of spacecraft [5].Normal buck converter topology has many disadvantage like non-continuous output current, leads to have large value of capacitor [6].

Manuscript received on April 02, 2020.

Revised Manuscript received on April 14, 2020.

Manuscript published on May 30, 2020.

* Correspondence Author

Anand E P *, EE Dept., NSS College of engineering, Palakkad, India. Email: anandep666@gmai.com

Priya G Das, EE Dept., NSS College of engineering, Palakkad, India. Email: priyadas27@gmail.com

(C) The Authors. Published by Blue Eyes Intelligence Engineering and Sciences Publication (BEIESP). This is an open access article under the CC BY-NC-ND license (http://creativecommons.org/licenses/by-nc-nd/4.0/)
To overcome these issues, Weinberg topology based converters are used. Converter has isolated and non-isolated versions. Space agencies are using isolated converter for as BDR [1].One of the most important part of the spacecraft is the battery discharge regulator. Because it regulating the power bus voltage and serve entire power required for the space craft [3].

\section{OPERATING MODES}

Fig. 1 shows the schematic diagram of Weinberg converter. It consists of a push pull transformer, coupled inductor (L1), switches (Q1 and Q2), output filter capacitor (C) and diodes for rectification (D 1 to D 4).

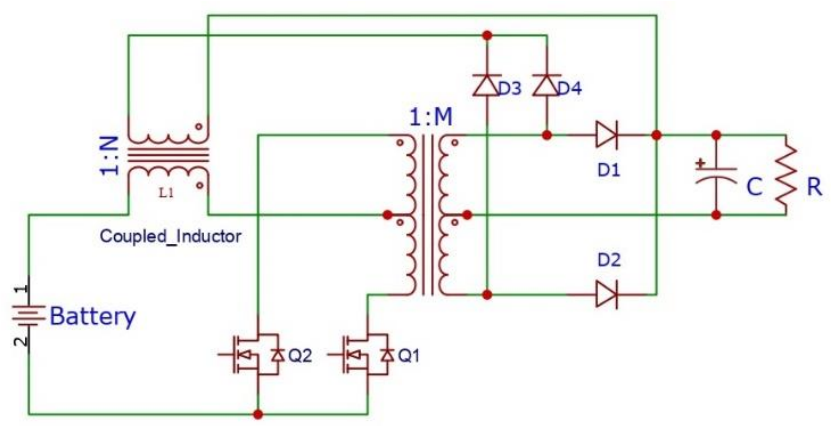

Fig. 1. Weinberg converter

Weinberg converter topology can be treat as push-pull converter fed by series connected coupled inductor. The design of coupled inductor ensuring the continuous mode of conduction of the converter. Converter working is explained with five modes of operation.

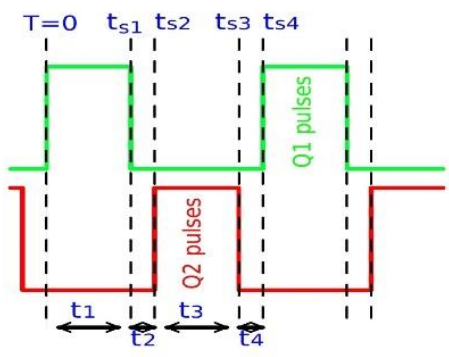

Fig.2. Switching pulses

\section{A. Mode 1:Q1 ON, Q2 OFF}

Mode 1 operation occur during the time interval t1 in switching pulses show in Fih.2. Corresponding equivalent circuit for converter is displayed in Fig.3.Dotted lines showing the current path when switch Q1 is conducting during the mode 1 operation. The primary current travel to the transformer via coupled inductor and back to the battery. Coupled inductor store energy during this mode. 


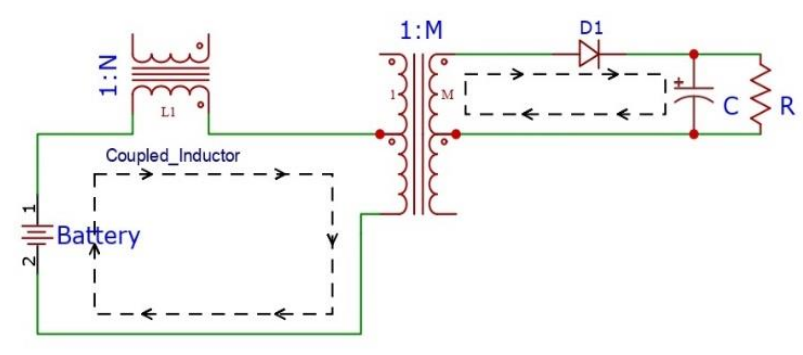

Fig.3. Mode 1 operation

Secondary current will flow through diode D1 to the load.

\section{A. Mode 2: Q1 OFF, Q2 OFF}

When both switch are OFF coupled inductor come in action. Previously stored energy from the coupled inductor transfer to the load side of the converter. Fig. 4 and Fig. 5 showing the equivalent circuit for this mode of operation. Diode D3 or D4 will conduct to transfer the energy to secondary.

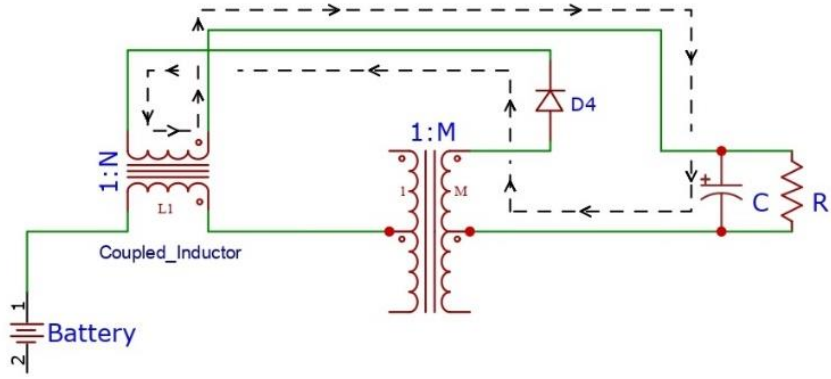

Fig.4. Mode 2 operation (D4 conducting)

The path of the current depends on which switch is turned on in the previous mode. This mode makes the load current continuous even the switches are off.

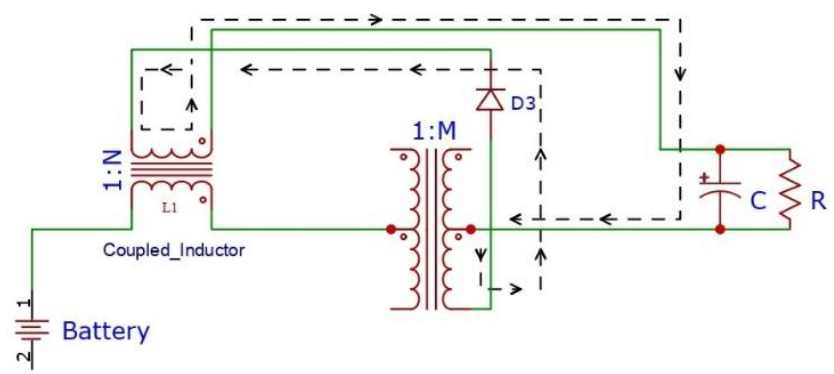

Fig.5. Mode 2 operation (D3 conducting)

\section{B. Mode 3: Q1 OFF, Q2 ON}

Equivalent circuit of mode 3 is displayed in Fig. 6. When switch Q2 is ON, the current flow to the transformer via coupled inductor and back to the battery. Diode D2 become forward biased and current flows to the filter capacitor and the load through the diode.

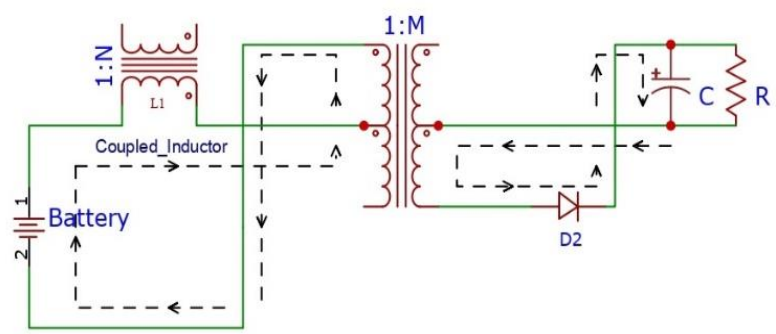

Fig.6. Mode 3 operation

\section{Mode 4: SWITCH IN FAULT CONDITION}

If any of the switch fails as open circuit the energy transfer in the corresponding mode get interrupted. During the time interval $\mathrm{t} 1$ or $\mathrm{t} 3$ depend on the switch failed, transfer of energy to the secondary will be interrupted.

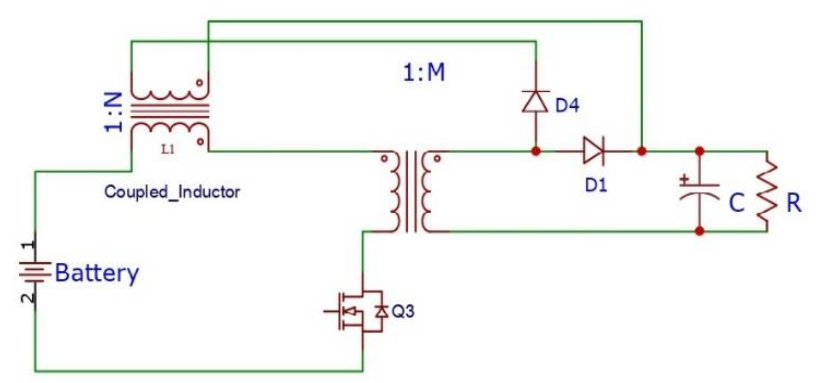

Fig.7. Mode 4 operation

In that case PWM controller IC increase the duty cycle to the switches and converter design is done such a way that one switch operation can also build the required output voltage.

\section{Mode-5: Q1 AND Q2 ON}

This mode is not desire in any converter. If the switches Q1 and Q2 are conducting simultaneously at any condition, Fig.8 giving the equivalent circuit of mode 5 .

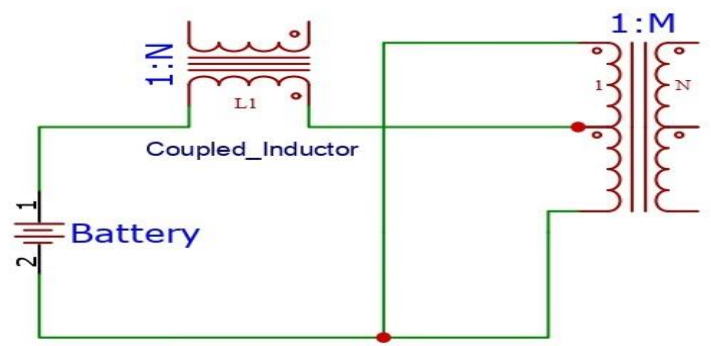

Fig.8. Mode 6 operation

When this condition arise, current at primary side of the transformer divides to half and conducts through the both limb of the transformer. This opposite direction of current flow generate a self-cancelling magnetic flux on the transformer. Hence no magnetization exists in the transformer core of the converter. Since the current flow there at the primary side, the coupled inductor store energy are prevent short circuit at the battery. 


\section{SPECIFICATION AND DESIGN}

\section{Parameter}

Input voltage $\left(\mathrm{V}_{\text {in }}\right)$

Output voltage $\left(\mathrm{V}_{\mathrm{o}}\right)$

Output power $\left(\mathrm{P}_{\mathrm{o}}\right)$

Output voltage ripple $\left(\Delta \mathrm{V}_{\mathrm{o}}\right)$

Switching frequency $\left(\mathrm{f}_{\mathrm{s}}\right)$

\section{Specification}

$42 \mathrm{~V}$ to $63 \mathrm{~V}$

$24 \mathrm{~V}$

$200 \mathrm{~W}$

$0.2 \mathrm{~V}_{\mathrm{pk}-\mathrm{pk}}$

$40 \mathrm{kHz}$
The ratio of output voltage to the input voltage may be written as [6],

$$
\frac{V_{0}}{\operatorname{Vin}}=\frac{D}{\frac{1-D}{M}+\frac{D}{N}}
$$

$\mathrm{D}$ is the ratio of on time of switch to the total time period. Input voltage to the converter is taken as the swing voltage of fifteen lion battery connected in series, and it will vary between $42 \mathrm{~V}$ to $63 \mathrm{~V}$ for the battery bank. The transformer ratios are chosen by keeping the maximum duty ratio below 0.4 for minimum battery voltage. At maximum battery voltage, the duty ratio should be minimum. SG3525 PWM generating IC is used, it can supply to the load by varying the width of pulses to the switch.

The values of the components can be calculates as [3],

- Load resistance Ro= $2.88 \mathrm{ohm}$

- Load current Io=8.3 Amps

- Coupled inductance value

$$
L=\operatorname{RoDVin}(1-D) T s / N * V o=28 \mu \mathrm{H}
$$

- Output filter capacitor $=470 \mu \mathrm{F}$

Fig.9 is the main part of the converter, in hardware implementation IRF740 MOSFETs are used and BYQ28 diodes are used at the power rectifier stage of the converter. Coupled inductor output is also connected to the load using diodes. For the feedback to the switching IC a voltage divider circuit with resistor are used.

For the control of switching and maintaining constant output voltage well know IC SG3525 is used as in Fig.11. The IC itself features optimum control for the push-pull topology based converter with built in MOSFET driver, a pin for stable reference voltage output and vide range supply voltage input.

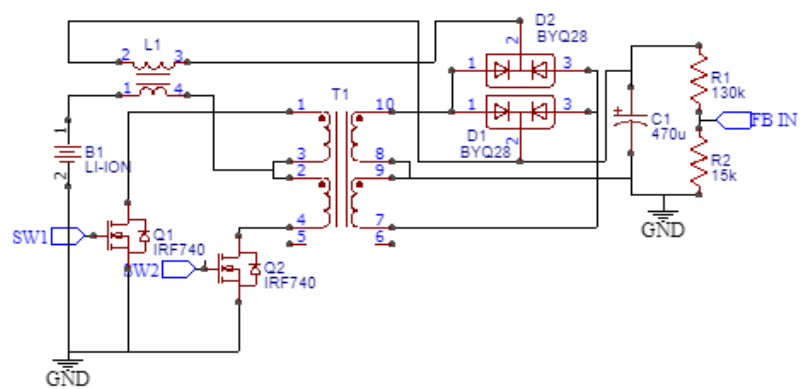

Fig.9. Hardware implemented circuit

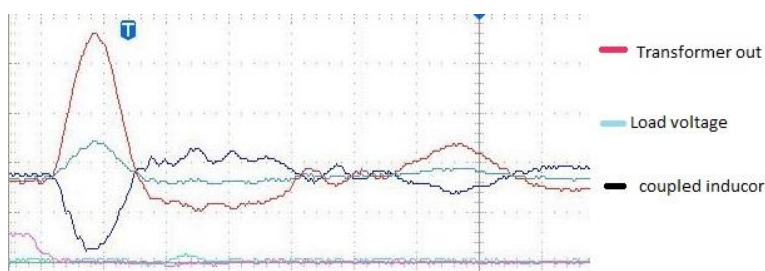

Fig.10.Voltage waveform

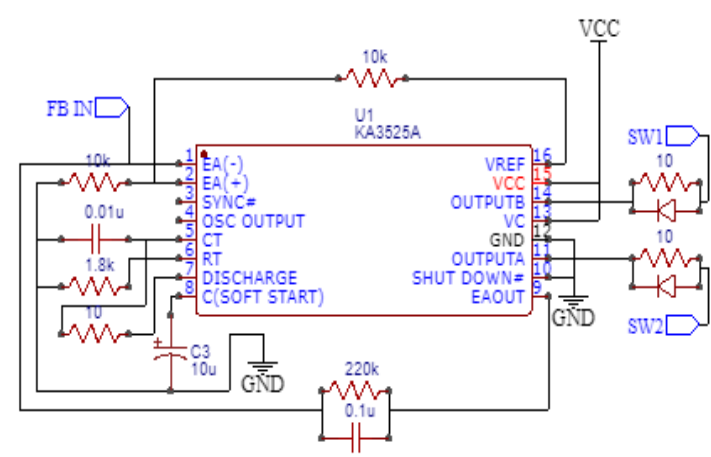

Fig.11.PWM generator circuit

\section{HARDWARE RESULT DISCUSSION}

Fig.10 showing the voltages of the coupled inductor, transformer output and the voltage measured across the load. The voltage appear across the load is the arbitrary sum of the other two voltages. Thus the ripple in voltage at the load is reduced.

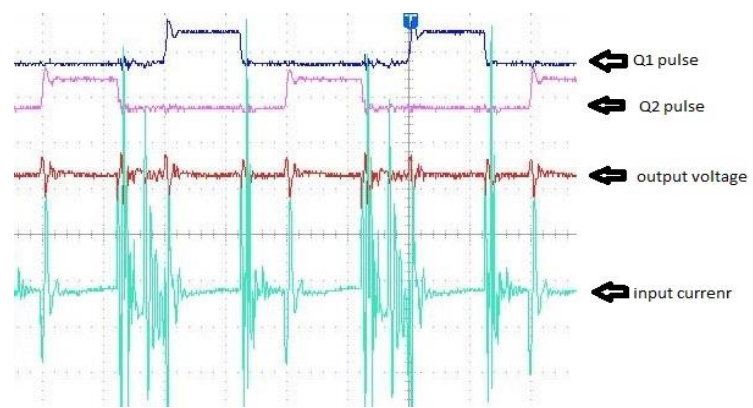

Fig.12. Waveform without coupled inductor

Fig.12, Fig.13 showing the effect of coupled inductor in the parameters of converter like duty ratio, voltage measured across the load and the input current. With coupled inductor the ripple in current is reduced considerably and also the ON time of switch is reduced, we can see improvement in the voltage measured across the load also.

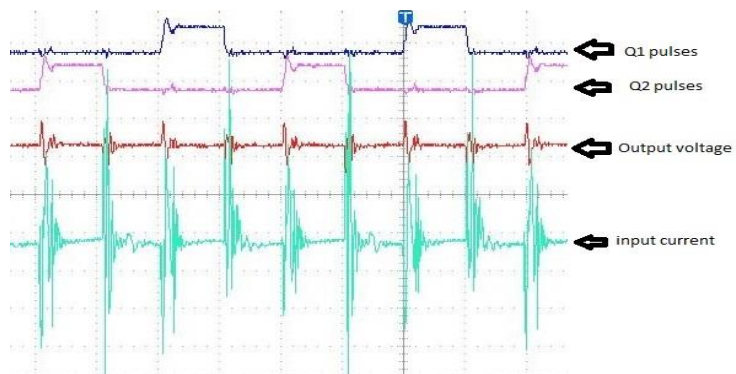

Fig.13. Waveform with coupled inductor

\section{CONCLUSION}

In a complete switching cycle Weinberg converter can supply power to the output from input. Thus the filter capacitor value can be reduced. This result is verified by developing a prototype of converter model rated at $200 \mathrm{w}$. 
By putting off gate drive pulse of one switch, fault tolerant feature is additionally tested. This increasing the reliability of the converter topology.

\section{ACKNOWLEDGEMENT}

The authors would like to thank Department of electrical and electronics engineering, NSS College of engineering, Palakkad for the laboratory support and KSCSTE SARD scheme for providing financial support for procuring equipments.

\section{REFERENCES}

1. G. Yadav, Gowrishankara C.K and Hariharan V.K., "Analysis and development of Weinberg converter with fault tolerant feature," 2016 Biennial International Conference on Power and Energy Systems: Towards Sustainable Energy (PESTSE), Bangalore, 2016, pp. 1-6. Sustainable Energy (PESTSE), 2016, no. C, pp. 4673-6658.

2. Ching-Yao Hung, C. Q. Lee and H. T. Lee, "Modeling of high power DC/DC converter system based on Weinberg topology," Proceedings of PESC '95 - Power Electronics Specialist Conference, Atlanta, GA, USA, 1995, pp. 1222-1228 vol.2.

3. E. Maset, A. Ferreres, J. B. Ejea, E. Sanchis-Kilders, J. Jordan and V. Esteve, "5kW Weinberg Converter for Battery Discharging in High-Power Communication Satellites," 2005 IEEE 36th Power Electronics Specialists Conference, Recife, 2005, pp. 69-75.

4. S. Kanta, B. Plangklang, and W. Subsingha, "Bi-directional DC/DC Converter for Hybrid Battery” Energy Procedia., 2014, vol. 56, no. C, pp. 604-609.

5. A.H Weinberg" A Boost Regulator with a New Energy-Transfer Principle", in proceedings of the Spacecraft Power Conditioning Electronics Seminar. 1974. pp. 115-122.

6. P. Kornetzky, Z. Moussaoui, I. Batarseh, Susan Hawasly, Chester Kennedy "Mode1ing Technique for DC to DC Converters using Weinberg Topology" in proc of the Florida Space Grant Consortium Program. 1995.

\section{AUTHORS PROFILE}

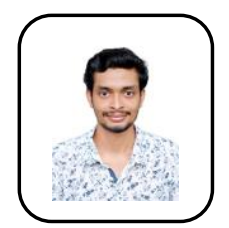

Anand EP, currently pursing master's degree in power electronics profile at NSS College of engineering Palakkad. Completed bachelor's degree in electrical and electronics engineering from MES College of engineering, Kuttippuram in 2018.

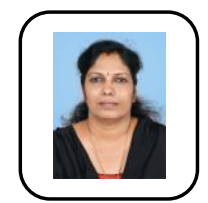

Dr.Priya G Das, Professor, Dept of Electrical \& Electronics, NSS College of Engg, Palakkad, has 26 years of teaching experience ce. Completed Pd.D. in aerospace from IISc, Bangalore. Published the work in journals and conferences. 